\title{
JAK3/STAT3 oncogenic pathway and PRDM1 expression stratify clinicopathologic features of extranodal NK/T-cell lymphoma, nasal type
}

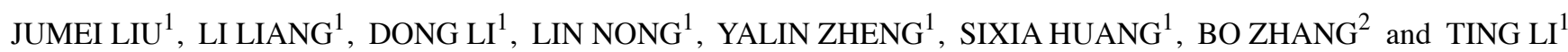 \\ ${ }^{1}$ Department of Pathology, Peking University First Hospital, Beijing 100034; \\ ${ }^{2}$ Department of Pathology, Peking University Health Science Center, Beijing 100191, P.R. China
}

Received July 19, 2018; Accepted April 9, 2019

DOI: $10.3892 /$ or.2019.7112

\begin{abstract}
The inactivation of tumor suppressor gene positive regulatory domain containing I (PRDM1) and activation of signal transducer and activator of transcription 3 (STAT3) have been detected in the majority of extranodal NK/T-cell lymphoma, nasal type (EN-NK/T-NT) cases. In the present study, their association with and effects on the clinicopathologic features of EN-NK/T-NT are described. PRDM1 was revealed to be expressed in 19 out of 58 patients (32.8\%) with EN-NK/T-NT, and phosphorylated STAT3 was overexpressed in 42 out of 58 (72.4\%). Oncogenic pathways were investigated by NanoString encounter technology in 5 PRDM1(+) and 5 PRDM1(-) EN-NK/T-NT specimens. Multiple oncogenic pathways involved in cell apoptosis, cellcycle (CC) and angiogenesis were discriminately activated in EN-NK/T-NT cases, and in PRDM1(+) cases in particular. The sustained activation of the Janus kinase 3 (JAK)/STAT3 pathway was more pronounced. In addition, missense mutations in the SRC homology 2 domain of STAT3 were detected in 7 out of 37 EN-NK/T-NT cases (18.92\%), and the acquired mutation was related to the activation of the JAK3/STAT3 pathway. The downregulation of PRDM1 and upregulation of phospho-STAT3 (Tyr705) were associated with angiocentric infiltration of EN-NK/T-NT $(\mathrm{P}=0.039)$. Notably, the prognosis of patients in the PRDM1(+)/STAT3 [mutated (mut-)]
\end{abstract}

Correspondence to: Dr Ting Li, Department of Pathology, Peking University First Hospital, 8 Xishiku Street, Xicheng, Beijing 100034, P.R. China

E-mail: lixiaoting12@hotmail.com

Abbreviations: NKTCL, NK/T-cell lymphoma; EN-NK/T-NT, extranodal NK/T-cell lymphoma, nasal type; STAT3, signal transducer and activator of transcription 3; p-STAT3, phospho-STAT3 (Tyr705); PRDM1, positive regulatory domain containing I; FFPE, formalin-fixed paraffin-embedded; $\mathrm{CC}$, cell cycle; OS, overall survival; WT, wild-type; mut, mutated

Key words: PRDM1, STAT3, extranodal NK/T-cell lymphoma, nasal type, tofacitinib group was considerably improved than that of patients in the STAT3(mut+)/PRDM(-) group $(\mathrm{P}=0.037)$. In addition, the inhibition of NK/T cell lymphoma cell lines by Stattic and tofacitinib could suppress cell proliferation by inducing cell apoptosis or arresting the $\mathrm{CC}$. The present results revealed that the JAK3/STAT3 oncogenic pathway and PRDM1 expression could stratify clinicopathologic features of EN-NK/T-NT. The inhibition of the JAK3/STAT3 pathway may serve as a treatment option for EN-NK/T-NT.

\section{Introduction}

Extranodal NK/T-cell lymphoma, nasal type (EN-NK/T-NT) is a highly aggressive non-Hodgkin lymphoma, characterized by prominent tumor necrosis and angiocentric invasion. Neoplastic cells are cytoplasmic CD3ع(+), CD56(+), cytotoxic-molecule(+) and Epstein-Barr virus(+) (1). This type of lymphoma usually occurs in the upper airway tract, mostly in the nasal and paranasal area, and is more prevalent among Asian and South American populations (2). In recent years, disease outcome has improved with chemotherapy and radiotherapy, but the prognosis remains poor, with a 5-year overall survival (OS) rate of $42-70 \%(3,4)$. The underlying pathogenesis of the disease remains unclear, and no effective targeted therapy is currently available.

Array comparative genomic hybridization and geneexpression profiling in EN-NK/T-NT revealed that the $6 \mathrm{q} 21$ regions most frequently deleted involve the downregulation of several important tumor-suppressor genes, such as POPDC3, PREP, positive regulatory domain containing I (PRDM1), ATG5, AIM1, HACE1 and FOXO3 $(5,6)$. Recent studies identified PRDM1, a tumor suppressive transcriptor, as being frequently inactivated in EN-NK/T-NT (7). Its inactivation may be associated with the combination of 6q21/PRDM1 gene deletion, PRDM1 mutation, aberrant upregulation of miRNA and/or an epigenetic mechanism (8-11). Our team previously reported that the hypermethylation of PRDM1 played a predominant role in the downregulation of PRDM1 expression, significantly affecting the biological behavior of tumor cells in EN-NK/T-NT. Notably, the PRDM1 expression exerted an effect on the outcome of patients $(10,11)$. Thus, PRDM1 expression has an important clinical prognostic 
value, and its inactivation may be an important pathogenetic mechanism for EN-NK/T-NT.

Gene-expression profiling also detected the activation of several oncogenic pathways in EN-NK/T-NT, including those of NF- $\kappa \mathrm{B}$, mitogen-activated protein kinase (MAPK), and Janus kinase 3/activator of transcription 3 (JAK3/STAT3) $(8,12,13)$. The JAK3/STAT3 pathway is known to play a crucial role in regulating cell growth, survival, motility and cell differentiation through the regulation of several downstream genes (14). The STAT3 protein is a key factor in JAK3/STAT3 pathway activation, and phospho-STAT3 (Tyr705) (p-STAT3) the activated status of STAT3. The phosphorylated form of STAT3 was detected in cell lines and the majority of the NK/T cell lymphoma primary tumors, and it may be associated with STAT3 gene mutation (15-17).

Although PRDM1 gene inactivation and the JAK3/STAT3 pathway play significant roles in the pathogenesis of EN-NK/T-NT, the association between them and their roles in EN-NK/T-NT are elusive. In the present study, oncogenic pathways were clarified in EN-NK/T-NT. The expression of PRDM1, activation of STAT3, and their genomic statuses were detected. In addition, potential clinical roles of PRDM1 and p-STAT3 were evaluated.

\section{Materials and methods}

Patients and samples. Archived formalin-fixed paraffinembedded (FFPE) tumor blocks were collected from 58 Chinese patients ( 35 males and 23 females; median age, 47 years old) diagnosed with EN-NK/T-NT from the Department of Pathology, Peking University First Hospital (Beijing, China). Thirty of the primary EN-NK/T-NT cases included in this study have been described in previous studies. The diagnosis of EN-NK/T-NT was confirmed according to the WHO classification (18). Follow-up data were available for 51 patients. The follow-up period was defined as the period from the date of initial diagnosis to the death of the patient (from any cause) or last follow-up.

Cell culture, treatment and viability. Three nasal NK/T cell lymphoma cell lines were used in the present study: NKL (19), NK92 (20) and YT (21). YT and NKL cells were obtained from Beijing Hong Bo Kang Biological Technology (Beijing, China). NK92 cells were purchased from the Chinese Academy of Medical Sciences (Beijing, China). The cell culture methods used have been described in our previous study (9). Cells were seeded at $2 \times 10^{5}$ cells $/ \mathrm{ml} /$ well in 24 -well plates and treated with tofacitinib (50 and $100 \mathrm{nM}$ ) (cat. no. 14703; Cell Signaling Technology, Inc., Danvers, MA, USA) and Stattic (1, 2, 5 and $10 \mu \mathrm{M}$ ) (cat. no. HY-13818; MedChemExpress, Inc., Shanghai, China) at indicated concentrations for 24 and $48 \mathrm{~h}$, with dimethyl sulfoxide (DMSO) used as the control, before being subjected to cell counting and MTS assays.

Immunohistochemistry (IHC). IHC was performed using the DAKO EnVision Detection Kit (Agilent Technologies, Inc., Santa Clara, CA, USA). The tissue sections were subjected to heat-induced antigen retrieval in EDTA buffer ( $\mathrm{pH} 9.0$ ), and a primary antibody against PRDM1 (dilution 1:100; cat no. 9115; Cell Signaling Technology; clone no. C14A4) or p-STAT3 (dilution 1:100; cat no. 9145; Cell Signaling Technology; clone no. D3A7) was used. A positive nuclear staining pattern was interpreted as PRDM1 or p-STAT3 immunoreactivity. Based on the studies by Garcia et al (22) and Nie et al $(23,24)$, the positive expression of PRDM1 nuclear staining was semi-quantitatively graded as follows: Negative ( 0 to $<10 \%$ positive cells) and positive ( $>10$ to $100 \%$ positive cells). A high expression of p-STAT3 was defined as moderate/strong nuclear staining in $\geq 50 \%$ of the tumor cell population and a low expression of p-STAT3 as $<50 \%$ nuclear staining $(16,17)$. Samples from the plasma cell myelomas and squamous epithelium of the nasal mucosa were used as positive controls for PRDM1 staining, and lung adenocarcinoma tissue and squamous epithelium of the nasal mucosa were used as a positive control for p-STAT3. For the negative control reactions, phosphate-buffered saline (PBS) was used instead of the primary antibody.

Western blot analysis. Cell lysis buffer (Nanjing Keygen Biotech, Co., Ltd., Nanjing, China) was used to lyse YT, NK92 and NKL cells and collect protein. BCA assay (Thermo Fisher Scientific, Inc., Waltham, MA, USA) was used to quantify protein concentration. A total of $40 \mu \mathrm{g}$ of protein from each sample was separated by electrophoresis in $10 \%$ sodium dodecyl sulphate polyacrylamide gels. After electroblotting the gels were transferred to polyvinylidene difluoride membranes (EMD Millipore, Billerica, MA, USA). The membranes were blocked with $5 \%$ milk for $1 \mathrm{~h}$ at room temperature, followed by incubation with a rabbit or mouse monoclonal antibody against PRDM1 (dilution 1:1,000; cat. no. 9115; Cell Signaling Technology; clone no. C14A4), p-STAT3 (Tyr705) (dilution 1:1,000; cat. no. 9145; Cell Signaling Technology; clone no. D3A7), STAT3 (dilution 1:1,000; cat. no. 4914; Cell Signaling Technology; clone no. 79D7), or $\beta$-actin (dilution 1:5,000; cat. no. TA346894; ZSGB-BIO, Inc., Beijing, China) overnight at $4^{\circ} \mathrm{C}$. Anti-rabbit and anti-mouse horseradish peroxidase-conjugated secondary antibodies (both dilution 1:5,000; cat. nos. ZB-2305 and ZB-2306; ZSGB-BIO, Inc.) were used to incubate for $60 \mathrm{~min}$ at room temperature. Enhanced chemiluminescence (EMD Millipore, Billerica, MA, USA) was used to develop protein signals. The band intensity of western blotting was measured by densitometry using the G:BOX Chemi XT4 (Syngene, Cambridge, UK). Protein expression was quantified by densitometry and normalized to $\beta$-actin.

PanCancer pathways analysis. According to our IHC grading criteria, 8 PRDM1(+) and 8 PRDM1(-) FFPE samples and 2 samples of normal nasal mucosa were selected from the $58 \mathrm{NK} / \mathrm{T}$ lymphoma cases. Total RNA was extracted using RNeasy Mini Kit (Qiagen GmbH, Hilden, Germany) according to the manufacturer's instructions. After determining the RNA quality using the Agilent 2100 Bioanalyzer (Agilent Technologies, Inc.), 5 PRDM1(+) and 5 PRDM1 (-) specimens (P1, P2, P3, P4, P5 and N1, N2, N3, N4, N5, respectively) that met the criterion of NanoString analysis were identified. The 2 normal nasal mucosa samples were used as blank controls (B1, B2). The NanoString nCounter PanCancer Pathways Panel (NanoString Technologies, Inc., Seattle, WA, USA) includes 770 essential genes representing 13 Canonical Pathways: Notch, Wnt, Hedgehog, TGF $\beta$, MAPK, STAT, 
P13K, RAS, chromatin modification, transcriptional regulation, DNA damage control, cell cycle (CC), and apoptosis. The NanoString nCounter assay was performed according to the standard protocol of NanoString with analysis and normalization of the raw NanoString data conducted using nSolver Analysis Software v3.0 (NanoString Technologies, Inc.). All procedures associated with mRNA quantification, including sample preparation, hybridization, detection and scanning, were carried out as recommended by NanoString Technologies, Inc.

Sanger sequencing. We were able to extract genomic DNA from 37 of the 58 FFPE specimens using DNeasy Blood \& Tissue kit (Qiagen $\mathrm{GmbH}$ ) according to the manufacturer's instructions. Sanger sequencing was used to confirm STAT3 SRC homology 2 (SH2)-domain mutations. STAT3 SH2-domain primer sequences were as follows: Exon 19-1 forward, 5'-TAG ACGGGCCTGAGGATTT-3' and reverse, 5'-CAAAGGGCC AGGATGTACTTT-3'; Exon 19-2 forward, 5'-AGACTTGGC TTTCCCATTACTC-3' and reverse, 5'-TTGCTAACAGGG CATCCATC-3'; Exon 20-1 forward, 5'-GCTCTCAGCAAG CCAGT-3' and reverse, 5'-TCACTGAATCTTAGCAGGAAG G-3'; Exon 20-2 forward, 5'-GGAGCGGGCCATCTTGA-3' and reverse, 5'-CTCAGCAGCCACCAGCA-3'; Exon 21-1 forward, 5'-TCTCTGAGATGACCTAGCTGTAG-3' and reverse, 5'-CCA TGATCTTATAGCCCATGATGA-3'; Exon 21-2 forward, 5'-GTCCGTGGAACCATACACAA-3' and reverse, 5'-GCTCTC TGGCCGACAATAC-3'; Exon 21-3 forward, 5'-CTCTATCCT GACATTCCCAAGG-3' and reverse, 5'-GCATTTGCCTAT CTATCCTCCA-3'; Exon 22 forward, 5'-TGCGAAGTCACA GTCAGTAAG-3' and reverse, 5'-GATTAACTCTCACCCAGT GTCC-3'. Polymerase chain reaction (PCR) was performed using Platinum Taq Polymerase (cat. no. 10966-083; Thermo Fisher Scientific, Inc., Waltham, MA, USA) cycled at $95^{\circ} \mathrm{C}$ for $10 \mathrm{~min}$, 45 cycles at $95^{\circ} \mathrm{C}$ for $30 \mathrm{sec}, 56^{\circ} \mathrm{C}$ for $30 \mathrm{sec}, 72^{\circ} \mathrm{C}$ for $1 \mathrm{~min}$, and a final extension of $72^{\circ} \mathrm{C}$ for $10 \mathrm{~min}$. PCR sequencing was carried out using ABI BigDye Terminator v3.1 (cat. no. 4337457; Thermo Fisher Scientific, Inc.) and cycled at $96^{\circ} \mathrm{C}$ for $1 \mathrm{~min}, 29$ cycles at $96^{\circ} \mathrm{C}$ for $10 \mathrm{sec}, 50^{\circ} \mathrm{C}$ for $5 \mathrm{sec}$ and $60^{\circ} \mathrm{C}$ for $4 \mathrm{~min}$. The resulting products were run on an $\mathrm{ABI} 3730 x 1 \mathrm{DNA}$ analyzer (Applied Biosystems; Thermo Fisher Scientific, Inc.).

Flow cytometry. The extent of drug-induced apoptosis and $\mathrm{CC}$ arrest was determined by staining with an Annexin V Apoptosis Detection kit I (BD Biosciences, San Jose, CA, USA) and Propidium Iodide Flow Cytometry kit (Abcam, Cambridge, MA, USA) following the manufacturer's instructions. Flow cytometry was performed using FACSAria II instruments and a FACSCalibur flow cytometer (both from BD Biosciences).

Statistical analysis. For the cell proliferation experiment, the data were obtained from at least 3 independent experiments, each with triplicate measurements $(n \geq 3)$. Statistical analysis of the data was performed using one-way ANOVA followed by Dunnett's post hoc test. P-values of $<0.05$ were considered to indicate a statistically significant difference. Fisher's exact test was used to analyze the association between STAT3 mutation and the clinical parameters of the subjects. The Spearman rank correlation coefficient test was used to determine the correlation between PRDM1 and p-STAT3 expression. OS was calculated using the Kaplan-Meier method and compared to log-rank tests. A two-sided $\mathrm{P}<0.05$ was considered to indicate a statistically significant difference. All analyses were performed using SPSS 19.0 software (IBM Corp., Armonk, NY, USA).

\section{Results}

p-STAT3 and PRDM1 expression in EN-NK/T-NT. To determine the activation status of STAT3 and the expression of PRDM1 in EN-NK/T-NT, IHC analysis of PRDM1 and p-STAT3 was performed in 58 cases of EN-NK/T-NT. The results revealed that $32.8 \%(19 / 58)$ of the cases exhibited weak, moderate or strong nuclear staining of PRDM1 ( $\geq 10 \%$ positive cells) (Fig. 1A and C). p-STAT3 was highly expressed in $72.4 \%(42 / 58)$ of the EN-NK/T-NT cases. The staining intensity of p-STAT3-positive cells was strong in the majority of cases (Fig. 1B and C). The expression of PRDM1 and p-STAT3 in malignant NK cell lines was also examined by western blot analysis. As revealed in Fig. 1D, the expression level of p-STAT3 was higher in YT and NKL than in NK92 cells, whereas PRDM1 was highly expressed in the YT, but not in the other 2 cell lines. These results demonstrated that STAT3 was frequently activated and PRDM1 commonly downregulated in EN-NK/T-NT.

Activation of JAK3/STAT3 pathway and its correlation with the status of PRDM1 in EN-NK/T-NT. To identify whether the JAK3/STAT3 pathway plays a predominant role in EN-NK/T-NT tumors, a panel of 13 classical oncogenic pathways was selected to perform gene expression analysis using the NanoString nCounter ${ }^{\circledR}$ system. A total of 10 [5 PRDM1(+) and 5 PRDM1(-)] EN-NK/T-NT and 2 normal nasal mucosa samples were assessed. First, the scoring of 13 pathways in each case was analyzed using unsupervised hierarchical clustering. As revealed in the heat map (Fig. 2A), 5 EN-NK/T-NT tumor samples (i.e., N4, N3, P1, P5 and P2) scored highly in the Wnt, RAS, apoptosis, STAT, TXmisReg, TGF $\beta$ and PI3K signaling pathways, suggesting the strong activation of these pathways in EN-NK/T-NT. P3 and P4 also scored highly in the STAT pathway (Fig. 2A), indicating the aberrant activation of the STAT pathway in the detected EN-NK/T-NT samples. The expression patterns of major genes in STAT pathways in EN-NK/T-NT were further analyzed. Fig. 2B reveals that the STAT pathway scores were much higher in the EN-NK/T-NT tumor samples than in the control (fold change $>7$ ). The heat maps in Fig. 2C further illustrated the expression levels of individual genes involved in the JAK/STAT pathway in each case. As depicted in Fig. 2C, STAT pathway-activating genes (including JAK3, STAT3, STAT1, STAT4, MYC, PIM1 and $P C N A)$ were increased, while STAT pathway-suppressing genes (including IL17, PIK3CA, PIK3R and SOCS2) were decreased in the majority of EN-NK/T-NT samples, supporting an overall effect of JAK3/STAT3 activation on EN-NK/T-NT tissues.

The 10 cases were then divided into either the PRDM1(+) or the PRDM1(-) group, according to the PRDM1 IHC staining results. As depicted in the bar graph (Fig. 3A), STAT, DNA Repair and CC pathways were highly upregulated in the 

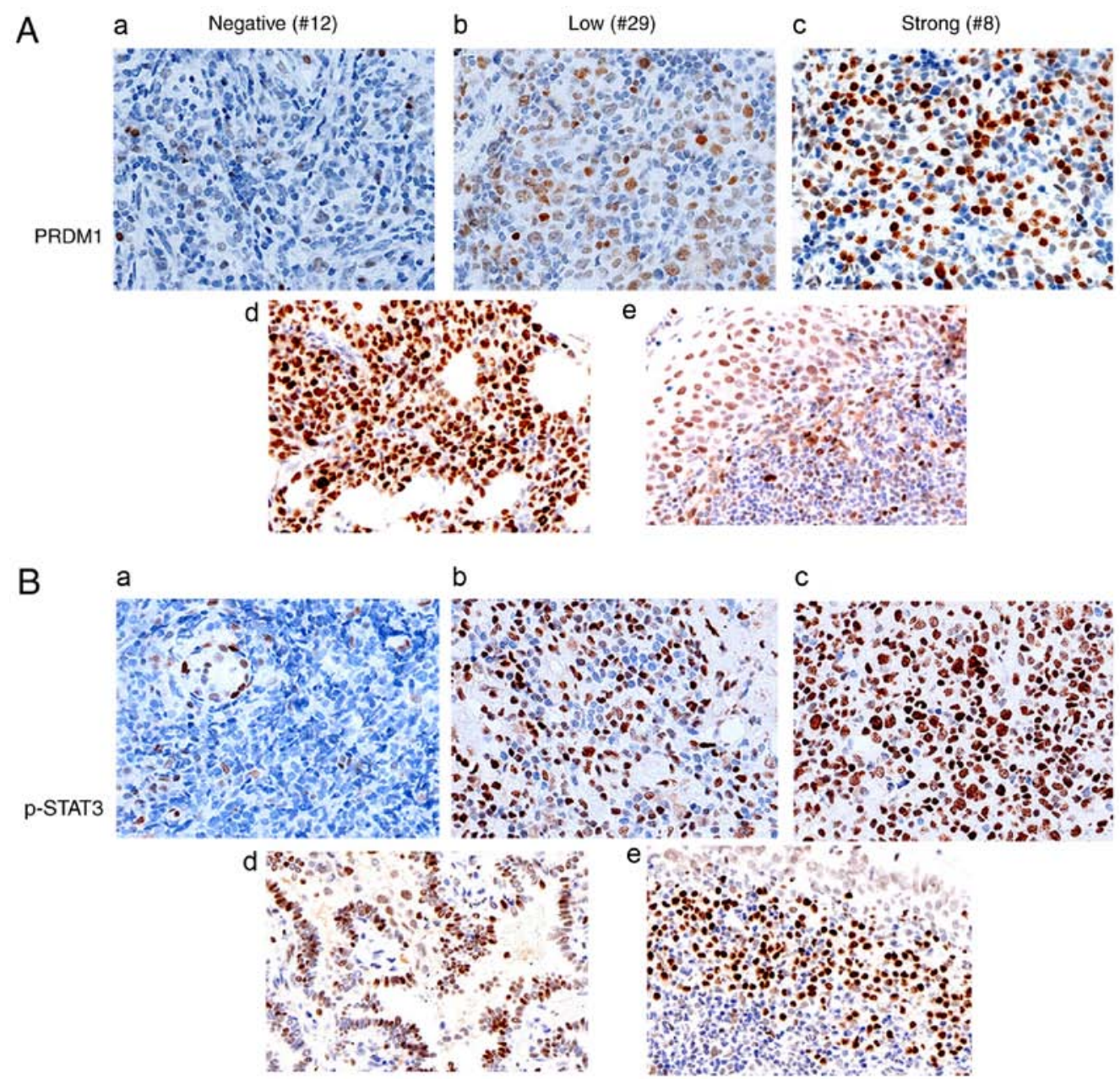

C
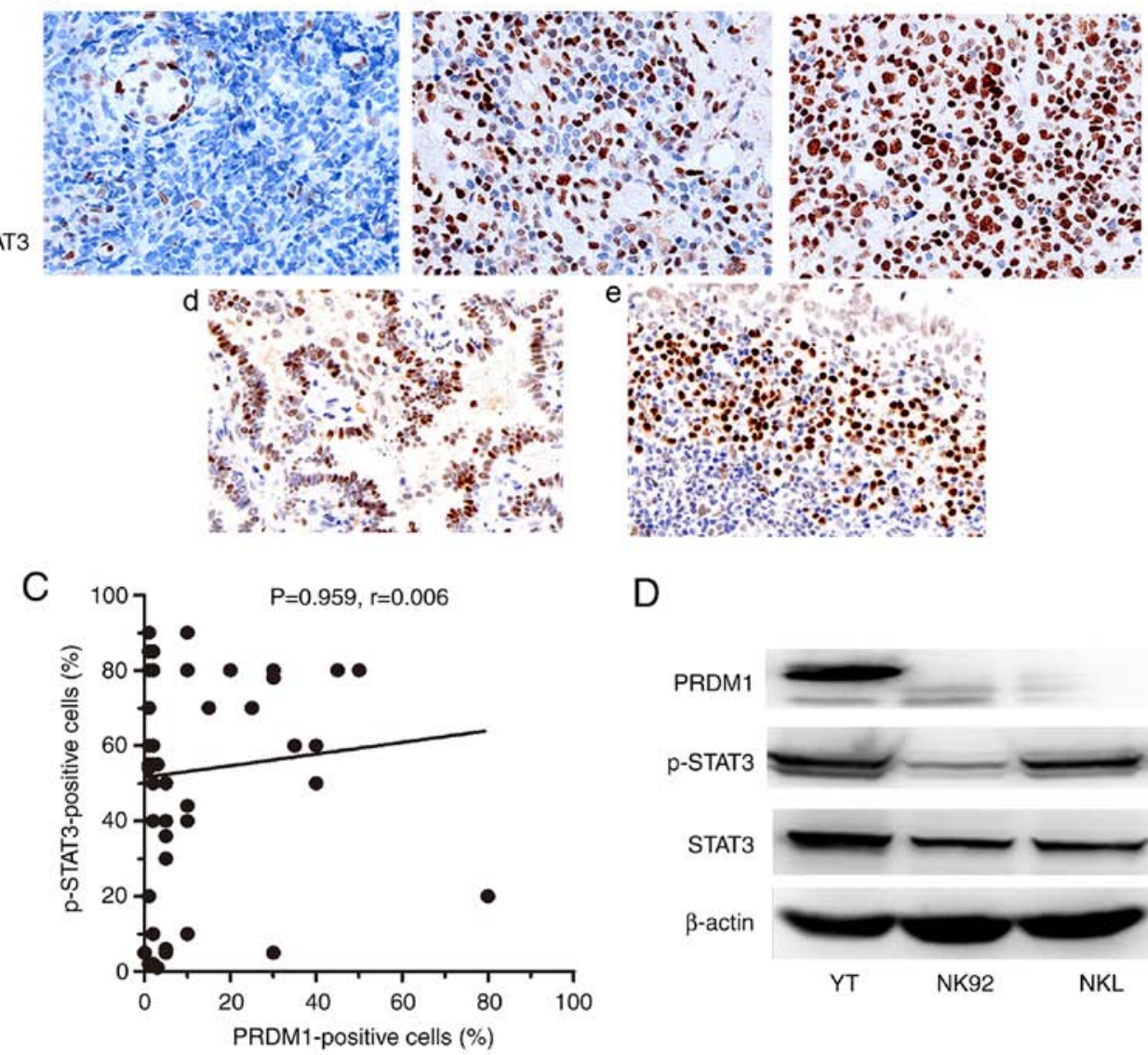

D

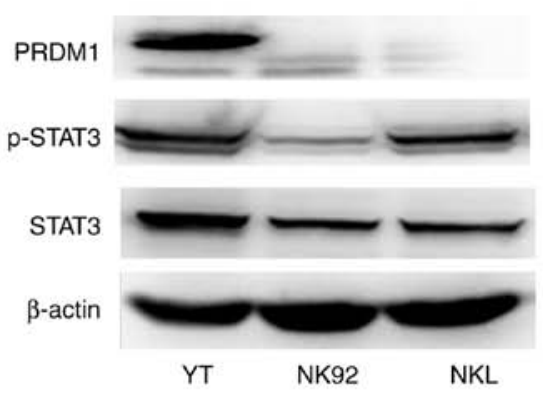

Figure 1. p-STAT3 and PRDM1 expression in EN-NK/T-NT. (A) Examples of IHC analysis of PRDM1 in EN-NK/T-NT specimens and control samples. In EN-NK/T-NT specimens, PRDM1 was commonly inactivated. Representative images of PRDM1 (a) negative, (b) low, and (c) high expression. (d) Samples from plasma cell myelomas, and (e) the squamous epithelium of nasal mucosa, were used as positive controls for PRDM1 staining. (B) Examples of IHC analysis of p-STAT3 in EN-NK/T-NT specimens and control samples. In EN-NK/T-NT specimens, p-STAT3 was commonly activated. Representative images of (a) p-STAT3 negative, (b) low, and (c) high expression. (d) Samples from adenocarcinoma tissue, and (e) the inflammatory nasal mucosa, were used as positive controls for $\mathrm{p}$-STAT3 staining. (C) A scatter plot revealed no direct correlation between PRDM1 immunostaining and $\mathrm{p}-\mathrm{STAT} 3 \mathrm{expression}$. (P=0.959, $\mathrm{r}=0.005$ ) (D) Western blot analysis of the expression level of STAT3, p-STAT3 and PRDM1 in YT, NKL and NK92 cells. p-STAT3, phospho-STAT3 (Tyr705); PRDM1, positive regulatory domain containing I; EN-NK/T-NT, extranodal NK/T-cell lymphoma, nasal type; IHC, immunohistochemistry.

two groups, although it was more marked in the PRDM1(+) group. Consistently, linear associations of pathway score analysis revealed that STAT, DNA repair and CC pathways were strongly activated in both the PRDM1(-) and PRDM1(+) groups (Fig. 3B and C). These results indicated that the activation of the STAT pathway may be independent from the PRDM1 expression in EN-NK/T-NT.
Genomic alterations of STAT3 and PRDM1 in EN-NK/T-NT. The strong p-STAT3 expression in the majority of EN-NK/T-NT cases prompted us to investigate the underlying mechanism of STAT activation. Recent studies have revealed that STAT3 mutations are highly associated with STAT3 activation in lymphoma cells. Since STAT3 mutations occur almost exclusively in its $\mathrm{SH} 2$ coding region, the $\mathrm{SH} 2$ domain-coding region of STAT3 

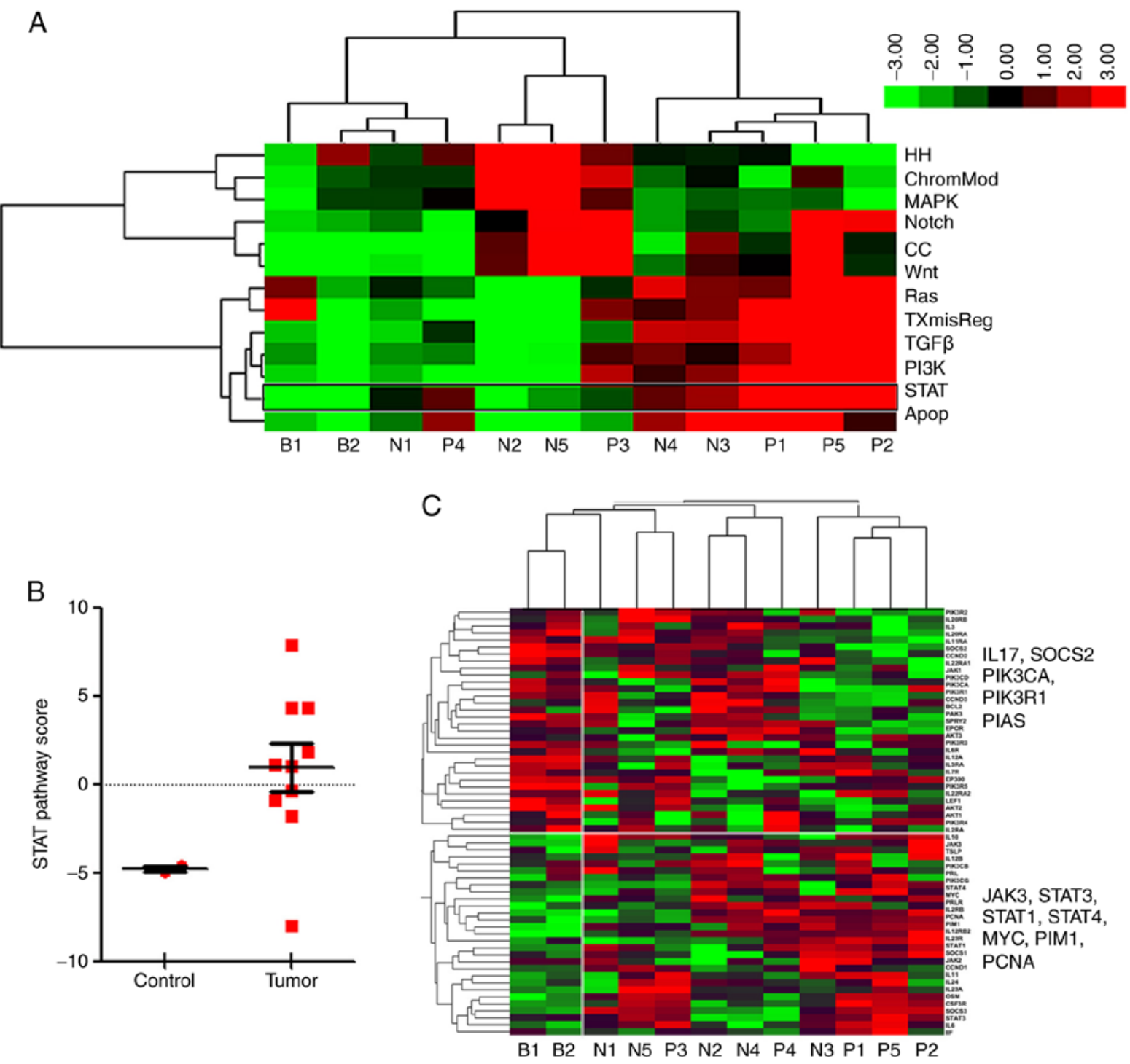

Figure 2. Activation of JAK3/STAT3 pathway in EN-NK/T-NT. NanoString nCounter analyzed 13 distinct oncogenic pathways and scored them using unsupervised hierarchical clustering between the tumor (group N+P) and blank groups (normal nasal mucosa specimens, group B). (A) Heat map scoring of 13 pathways for each case, demonstrated clear differences between normal and tumor specimens. Red indicates high expression and green low. Expression values were scaled within pathways. The 13 signaling pathways were divided into 3 clusters. Five EN-NK/T-NT cases (right) exhibited a cluster of high scores in the Wnt, RAS, apoptosis, STAT, TXmisReg, TGF $\beta$ and PI3K signaling pathways. (B) Box plots of pathway scores revealing clear differences in the STAT pathway scores between the tumor and normal nasal mucosa groups (control). Tumor cases had higher scores than the normal nasal mucosa cases (fold change $>7$ ). (C) Heat map indicating the expression level of genes associated with the STAT pathway. Red indicates high expression and green low. Expression values were scaled for genes. The expression of genes associated with STAT3 pathway activation was increased, whereas that of genes involved in the suppression of its activation was low in tumor samples. STAT3, signal transducer and activator of transcription 3; EN-NK/T-NT, extranodal NK/T-cell lymphoma, nasal type.

was sequenced in $3 \mathrm{NK} / \mathrm{T}$ lymphoma cell lines (YT, NKL and NK92) and 37 EN-NK/T-NT cases. Fig. 4A summarized all 6 missense mutation types detected in 2 lymphoma cell lines (Y640F in YT and NKL, but not NK92) and 7 EN-NK/T-NT cases (e.g., S614C in case no. 2). Fig. 2B presents the sequencing results of these missense mutations. The STAT3 missense mutation rate was $18.92 \%$ (7/37) (Table I). In addition, a silent mutation (G618G, GGG>GGT) was detected in $2 \mathrm{EN}-\mathrm{NK} / \mathrm{T}-\mathrm{NT}$ cases (case nos. 8 and 15). Notably, all 7 EN-NK/T-NT cases with STAT3 missense mutations exhibited a marked p-STAT3 expression (Table I), strongly indicating that STAT3 gene mutations in the $\mathrm{SH} 2$ domain is a driving force for the activation of the JAK3/STAT3 pathway in EN-NK/T-NT.

With respect to the PRDM1 genomic status, no correlation between the STAT3 gene mutation and 6q21/PRDM1 gene deletion was identified. Despite that, STAT3 activation, PRDM1 loss, and 6q21 and/or PRDM1 heterozygous deletion could simultaneously be detected in the NKL cell line and in 9 EN-NK/T-NT cases (case nos. 22, 28, 34, 36, 41, 42, 48, 52 and 55), suggesting that genetic alterations of STAT3 and PRDM1 could be independent events in the development of EN-NK/T-NT (Table II).

Stratified clinicopathological significance of STAT3 activation and PRDM1 expression in EN-NK/T-NT. To explore the clinicopathological significance of STAT3 mutations and PRDM1 activation and expression in EN-NK/T-NT, the survival effect of STAT3 expression and mutations was analyzed. Kaplan-Meier single-factor analysis and the log-rank test revealed that patients in the mutated STAT3 
A
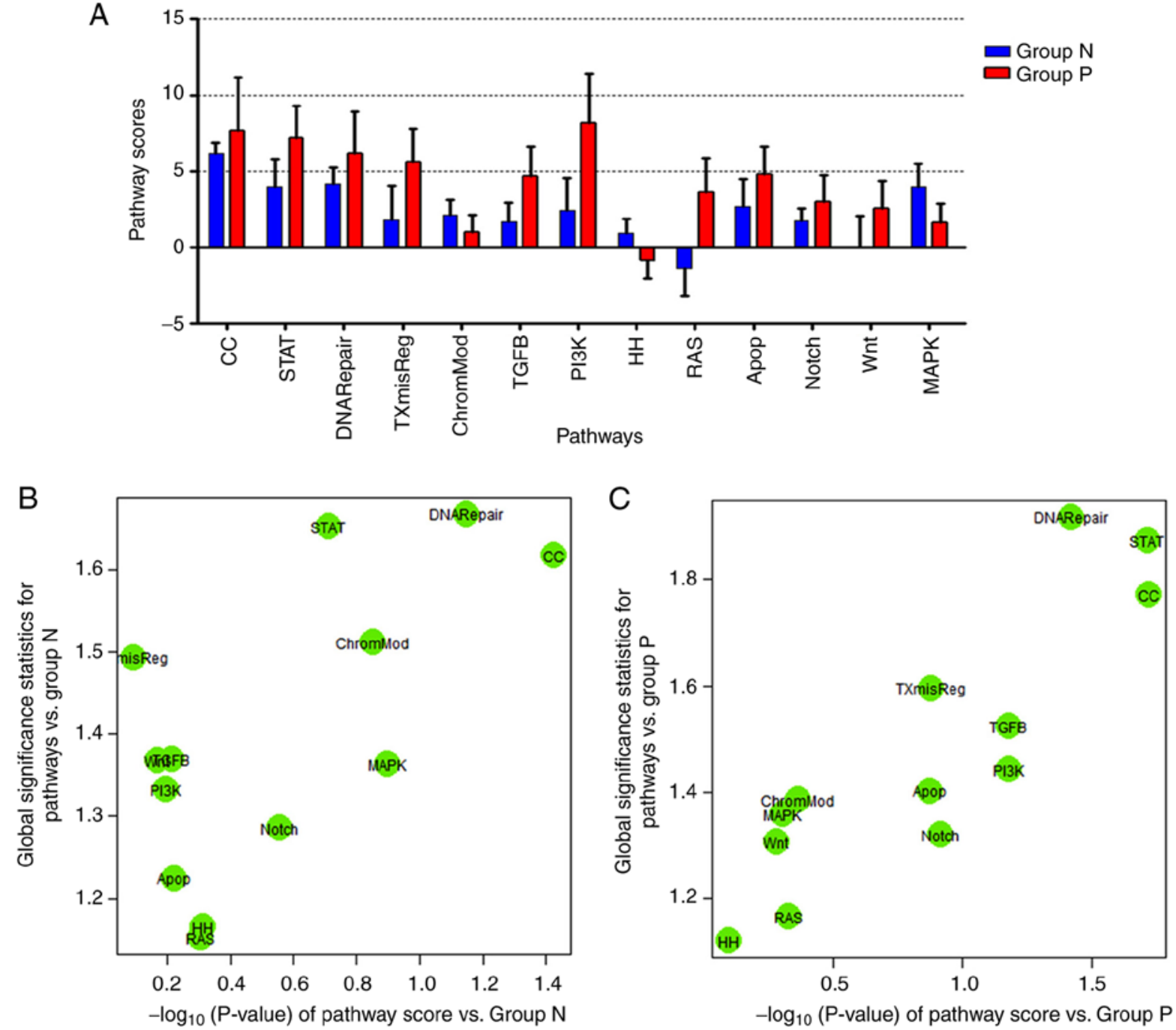

Figure 3. Correlation between the JAK3/STAT3 pathway and PRDM1 status in EN-NK/T-NT. (A) Pathway scoring results for each pathway in PRDM1(+) (group P) and PRDM1(-) (group N) cases revealed that STAT, DNA Repair and CC pathways were highly upregulated in both groups, particularly in PRDM1(+) cases. Global significance scores and linear associations plotted for each pathway in groups (B) N and (C) P, revealed that STAT, DNA Repair and CC pathways were highly upregulated in both groups. STAT3, signal transducer and activator of transcription 3; PRDM1, positive regulatory domain containing I; EN-NK/T-NT, extranodal NK/T-cell lymphoma, nasal type; CC, cell cycle.

group [STAT3(mut+)] had a considerably shorter survival time than those in the non-mutation group [STAT3(mut-)] (Fig. 5A; $\mathrm{P}=0.017$ ) while the $\mathrm{p}-\mathrm{STAT} 3$ level did not predict OS time in EN-NK/T-NT (Fig. 5B). In addition, STAT3(mut+) and p-STAT3(+) were revealed to be correlated with angiocentric infiltration but no other pathological factor (i.e., site, Ann Arbor Stage, outcome or necrosis) in EN-NK/T-NT (Table III). These findings indicated that STAT3(mut+) is a predictor for poor prognosis in patients with EN-NK/T-NT. The survival effect of PRDM1 expression was also analyzed. PRDM1(+) staining predicted a favorable effect on OS time (Fig. 5C; $\mathrm{P}=0.037)$. Furthermore, EN-NK/T-NT cases in this cohort were divided into 4 groups: PRDM1(+)/STAT3(mut-), PRDM1(+)/STAT3(mut+), PRDM1(-)/STAT3(mut-) and PRDM1(-)/STAT3(mut+). Notably, the majority of cases with PRDM1(-)/STAT3(mut+) resulted in a poorer prognosis (Fig. 5D; $\mathrm{P}=0.037$ ), as compared to the other groups, suggesting that detecting STAT3 mutations and PRDM1 expression may be useful for routine pathological diagnosis and patient prognosis.
Effects of inhibition of JAK3/STAT3 pathway on EN-NK/T-NT cells. The potential therapeutic application of suppressing the JAK3/STAT3 pathway in EN-NK/T-NT was explored. The cell viability of YT and NKL cells harboring STAT3 Y640F was inhibited by the STAT3 inhibitor Stattic (Fig. 6A). However, Stattic had a low toxicity in NK92 cells with wild-type STAT3, which usually exhibit relatively lower p-STAT3 levels than YT and NKL cells (Fig. 6A). To evaluate whether Stattic induces apoptosis, the apoptosis of various Stattic-treated cells was analyzed by flow cytometry. The treatment of YT and NKL cells with Stattic significantly increased apoptotic cells, when compared with DMSO-treated cells. However, no increase in the number of apoptotic cells was observed in NK92 cells (Fig. 6B). In addition, YT, NKL and NK92 cells were treated with tofacitinib, a JAK inhibitor, to further identify the biological effect of the JAK3/STAT3 pathway on NK/T cells. As revealed in Fig. 7A, not only did the number of NK92 cells significantly decrease following treatment with 50 and $100 \mathrm{nM}$ tofacitinib, but also the number of YT and NKL slightly decreased. However, tofacitinib did not alter 


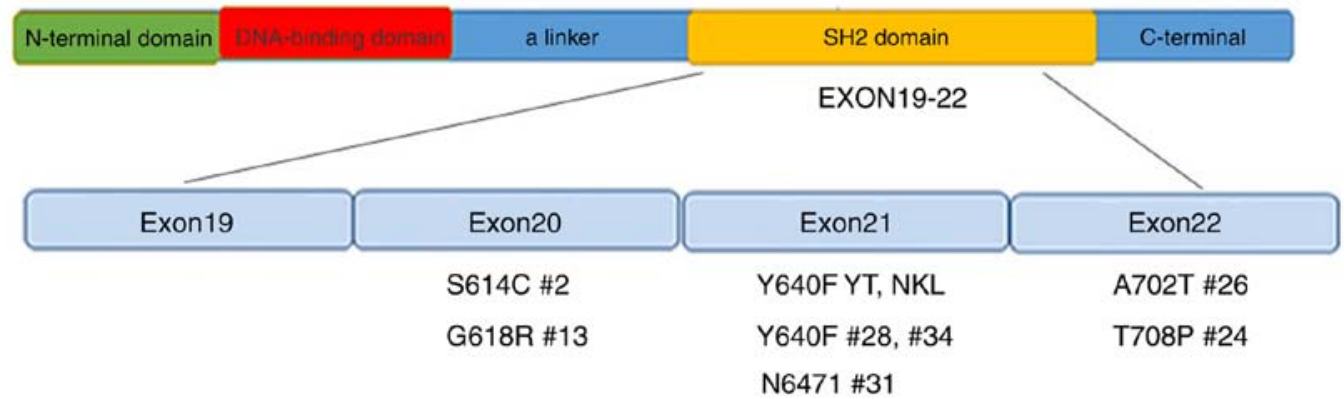

B

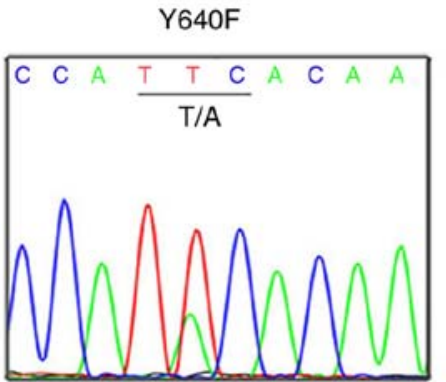

N647I

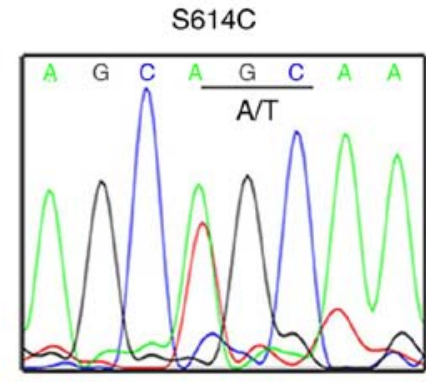

A702T
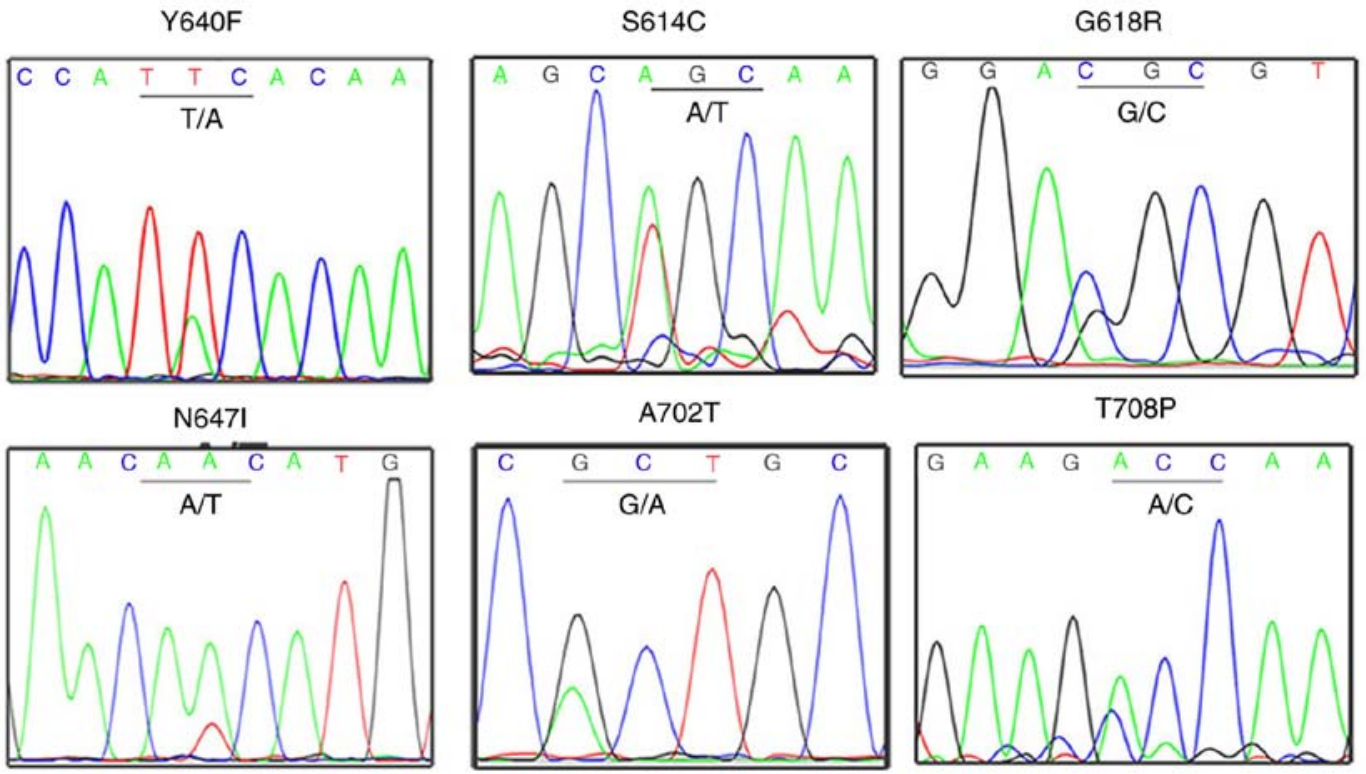

T708P

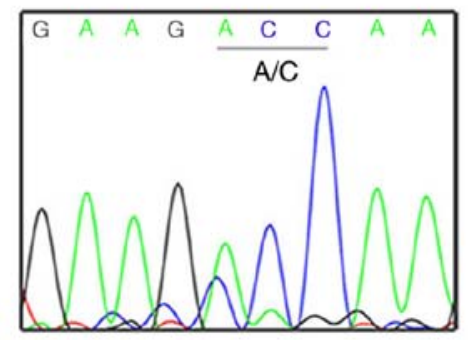

Figure 4. Genomic mutations of STAT3 in extranodal NK/T-cell lymphoma, nasal type. (A) Location of the mutated nucleotides in the SH2 domain of the STAT3 gene in tumor specimens and YT and NKL cell lines. (B) STAT3 missense mutation through Sanger sequencing. STAT3, signal transducer and activator of transcription 3; SH2, STAT3 SRC homology 2.

the number of apoptotic cells in the 3 cell lines (not shown). Next, the effect of tofacitinib on the CC was investigated. Flow cytometric analysis demonstrated that $100 \mathrm{nM}$ tofacitinib significantly increased the percentage of YT, NKL and NK92 cells at the G0/G1 phase with a concomitant reduction in the percentage of cells in the S (YT, NKL and NK92) and G2 (NK92) phases in the treated NK/T lymphoma cells, as compared with the control group (Fig. 7B). These findings indicated that suppressing the JAK3/STAT3 pathway may have a therapeutic effect in EN-NK/T-NT.

\section{Discussion}

NK cell malignancy is a multistep process, often involving the cooperation of tumor suppressor gene inactivation and oncogene activation. Previous studies have revealed that PRDM1 is a tumor suppressor gene in NK/T cell lymphomas, and PRDM gene deletion is a common event $(6,7)$. Karube et al using semi-quantitative RT-PCR detected PRDM1 expression in one representative donor and neoplastic samples and revealed that average expression of PRDM1 levels in neoplastic samples were significantly lower than those in normal NK cells (6). PRDM1 expression has been revealed to be associated with the stage of the disease and has a positive effect on prognosis (10). The present study also revealed
PRDM1 low expression in the majority of EN-NK/T-NT cases, and confirmed the effect of PRDM1 expression on the prognosis of EN-NK/T-NT.

Previous studies have revealed that the JAK/STAT signaling pathway is crucial for disease development. Gene-expression profiling also revealed that the JAK3/STAT3 signaling pathway was one of the discriminating pathways in NK/T lymphoma (13). The JAK family consists of 4 types: JAK1, JAK2, JAK3 and TyK2. Somatic mutations in JAK1, JAK2 and JAK3 result in constitutively active kinases in myeloproliferative diseases and leukemia/lymphomas. Somatic activating mutations in JAK1 and JAK2 have been mainly detected in acute lymphoblastic leukemia and myeloproliferative neoplasms (25). However, mutations in JAK3 have been mainly found in T- and NK cell lymphoma. In ENKTL, JAK3 phosphorylation has been detected in most cases. JAK3 activating mutations were identified in approximately one-third of the cases. In addition, a high expression of p-STAT3 has been detected in a variety of tumors, including colorectal, gastric and breast cancer, and non-Hodgkin lymphoma (25-27). Bouchekioua et al (28) and Nairismägi et al (29) using western blot analysis on the expression level of p-STAT3 expression in NK/T cell lines determined that p-STAT3 have a low/no expression in normal NK cells. However, p-STAT3 has been revealed to be overexpressed in tumor cell lines, as well as 
Table I. Clinicopathological features of 37 extranodal NK/T-cell lymphoma, nasal type.

\begin{tabular}{|c|c|c|c|c|c|c|c|c|}
\hline $\begin{array}{l}\text { Sample } \\
\text { no. }\end{array}$ & Sex & $\begin{array}{c}\text { Age } \\
\text { (years) }\end{array}$ & $\begin{array}{l}\text { Biopsy } \\
\text { site }\end{array}$ & $\begin{array}{l}\text { Ann Arbor } \\
\text { stage }\end{array}$ & $\begin{array}{l}\text { PRDM1 } \\
\text { expression }\end{array}$ & $\begin{array}{l}\text { p-STAT3 } \\
\text { expression }\end{array}$ & $\begin{array}{c}\text { STAT3 } \\
\text { mutation }\end{array}$ & Outcome \\
\hline Case 1 & M & 6 & Nasal & IV & High & High & No & Alive \\
\hline Case 2 & M & 49 & Nasal & I & High & High & S614C & Alive \\
\hline Case 3 & M & 63 & Nasal & II & Negative & High & No & Alive \\
\hline Case 4 & $\mathrm{~F}$ & 22 & Nasal & III & Negative & Negative & No & Alive \\
\hline Case 5 & M & 35 & Nasal & III & Negative & High & No & Died \\
\hline Case 6 & M & 66 & Skin & IV & Negative & Negative & No & Died \\
\hline Case 7 & M & 51 & Nasal & III & Negative & Negative & No & Alive \\
\hline Case 8 & M & 53 & Nasal & III & High & High & G618G & Alive \\
\hline Case 9 & $\mathrm{~F}$ & 41 & Inguinal lymph nodes & IV & Negative & High & No & Alive \\
\hline Case 10 & $\mathrm{~F}$ & 43 & Nasal & IV & High & High & No & Died \\
\hline Case 11 & M & 52 & Nasal & IV & High & High & No & Died \\
\hline Case 12 & M & 36 & Nasal & II & Negative & Negative & No & Alive \\
\hline Case 13 & M & 29 & Skin & III & Low & High & G618R & Alive \\
\hline Case 14 & M & 55 & Nasal & IV & Negative & Low & No & Died \\
\hline Case 15 & M & 48 & Nasal & II & High & Low & G618G & Alive \\
\hline Case 16 & F & 62 & Nasal & III & High & low & No & Died \\
\hline Case 17 & M & 77 & Nasal & II & High & High & No & Alive \\
\hline Case 18 & M & 47 & Nasal & IV & Negative & High & No & Died \\
\hline Case 19 & M & 29 & Nasal & III & High & High & No & Died \\
\hline Case 20 & $\mathrm{~F}$ & 25 & Nasal & IV & High & High & No & Died \\
\hline Case 21 & M & 66 & Tonsil & I & Low & High & No & Alive \\
\hline Case 22 & M & 80 & Nasal & IV & Low & Low & No & Died \\
\hline Case 23 & $\mathrm{~F}$ & 62 & Axillary lymph node & IV & Negative & High & No & Died \\
\hline Case 24 & $\mathrm{~F}$ & 38 & Skin & NA & Negative & High & T708p & Died \\
\hline Case 25 & $\mathrm{~F}$ & 81 & Nasal & III & High & High & No & Died \\
\hline Case 26 & M & 49 & Intestine & IV & Negative & High & A702t & Died \\
\hline Case 27 & $\mathrm{~F}$ & 55 & Bone marrow & II & Negative & Negative & No & Alive \\
\hline Case 28 & M & 28 & Skin & IV & Negative & High & Y640f & Died \\
\hline Case 29 & M & 45 & Nasal & I & Low & High & No & Alive \\
\hline Case 30 & M & 73 & Skin & IV & Negative & High & No & Died \\
\hline Case 31 & $\mathrm{~F}$ & 41 & Nasal & Iv & Negative & High & N647i & Died \\
\hline Case 32 & $\mathrm{~F}$ & 23 & Nasal & III & Negative & Negative & No & Alive \\
\hline Case 33 & F & 54 & Nasal & IV & Negative & Negative & No & Died \\
\hline Case 34 & M & 12 & Nasal & IV & Negative & High & Y640f & Died \\
\hline Case 35 & M & 63 & Tonsil & I & Low & High & No & Alive \\
\hline Case 36 & M & 71 & Nasal & I & Negative & High & No & Alive \\
\hline Case 37 & $\mathrm{~F}$ & 29 & Inguinal lymph nodes & II & Negative & High & No & NA \\
\hline
\end{tabular}

M, male; F, female; NA, data not available; PRDM1, positive regulatory domain containing I; STAT3, signal transducer and activator of transcription 3; p-STAT3, phospho-STAT3 (Tyr705); EN-NK/T-NT, extranodal natural killer/T-cell lymphoma, nasal type.

in most EN-NK/T-NT primary tumors $(16,17)$. In the present study, NanoString results revealed that the STAT pathway was activated in $70 \%$ of EN-NK/T-NT cases, IHC results revealed that p-STAT3 was highly expressed in $72.4 \%$ of EN-NK/T-NT samples, and western blot analysis results revealed that p-STAT3 was activated in NK/T cell lines. Therefore, JAK3/STAT3 was activated in the majority of the EN-NK/T-NT cases, demonstrating its important role.

It is well known that the JAK3/STAT3 pathway can be activated by two main mechanisms in EN-NK/T-NT, either by Epstein-Barr virus infection or by driver gene mutation $(12,17,30,31)$. Recently, next generation sequencing revealed that the frequencies of JAK3 (A572V, A573V) mutations were variable and relatively low (17,30,32-34). Sanger sequencing of the cases in the present study did not reveal these single nucleotide variants (data not shown), which was consistent with a recent study (35). By contrast, the STAT3 mutation rate was high and stable. In 4 published sequencing data, the mutation frequencies of the STAT3 gene was $12 \%(3 / 25), 26 \%(9 / 34), 10.5 \%(11 / 105)$ and $8 \%(2 / 25)$ in 
Table II. Summary of PRDM1 expression, combination of gene deletion, p-STAT3 expression and STAT3 mutation in EN-NK/T-NT.

\begin{tabular}{|c|c|c|c|c|}
\hline Sample & PRDM1 protein & 6q21 and/or PRDM1 HD & p-STAT3 & STAT3 mutation \\
\hline YT & + & - & + & Y640F \\
\hline NKL & - & + & + & Y640F \\
\hline NK92 & - & + & - & - \\
\hline Case 22 & - & + & + & - \\
\hline Case 26 & - & + & + & A702T \\
\hline Case 28 & - & + & + & Y640F \\
\hline Case 29 & + & - & + & - \\
\hline Case 33 & - & - & - & - \\
\hline Case 34 & - & + & + & Y640F \\
\hline Case 35 & + & - & + & - \\
\hline Case 36 & - & + & + & - \\
\hline Case 37 & - & + & - & ND \\
\hline Case 38 & - & + & - & ND \\
\hline Case 39 & - & + & - & ND \\
\hline Case 40 & - & - & + & ND \\
\hline Case 41 & - & + & + & ND \\
\hline Case 42 & - & + & + & ND \\
\hline Case 43 & - & - & + & ND \\
\hline Case 44 & - & + & - & ND \\
\hline Case 45 & - & + & - & ND \\
\hline Case 46 & + & + & + & ND \\
\hline Case 47 & - & - & + & ND \\
\hline Case 48 & - & + & + & ND \\
\hline Case 49 & - & - & + & ND \\
\hline Case 50 & - & - & - & ND \\
\hline Case 51 & + & - & + & ND \\
\hline Case 52 & - & + & + & ND \\
\hline Case 53 & + & + & + & ND \\
\hline Case 54 & - & - & - & ND \\
\hline Case 55 & - & + & + & ND \\
\hline
\end{tabular}

PRDM1, positive regulatory domain containing I; p-STAT3, phospho-STAT3 (Tyr705); STAT3, signal transducer and activator of transcription 3; EN-NK/T-NT, extranodal natural killer/T-cell lymphoma, nasal type; HD, heterozygous deletion; ND, no detection.

patients and/or cell lines, respectively $(17,30,32,33)$. Notably, all STAT3 mutations occurred at the $\mathrm{SH} 2$ domain. Therefore, frequent mutations in this domain can be presumed to be gain-of-oncogenic-function type mutations. In the present study, the SH2 domains of STAT3 in cell lines and primary tumors were sequenced. The STAT3 mutation was detected in $18.92 \%$ of EN-NK/T-NT cases, with an increased p-STAT3 expression also identified in those cases, demonstrating that the activation of the JAK3/STAT3 pathway may be partly caused by STAT3 mutations. Among the 6 types of missense mutations, T708P in STAT3 had not been previously reported. Notably, EN-NK/T-NT patients with STAT mutations had a considerably poorer OS. Therefore, STAT3 mutation is a prognostic marker for EN-NK/T-NT patients, but p-STAT3 is not.

Certain studies have indicated that STAT3 could mediate the upregulation of PRDM1, which in return inhibits STAT3 phosphorylation in B cells (36). ChIP-seq data have also confirmed that STAT3 has the potential to bind to multiple areas within PRDM1 (37). However, in the present study, the JAK3/STAT3 pathway was activated in both the PRDM1(+) and PRDM1(-) groups, although it was more marked in the PRDM1(+) group. The NKL cell line with PRDM1 deletion exhibited a high p-STAT3 expression, with the NK92 cell line with PRDM1 deletion exhibiting no p-STAT3 expression. In the present cohort, a high expression of p-STAT3 was detected in the majority of the EN-NK/T-NT cases, but there were only a few cases with a high expression of PRDM1. These results indicated that PRDM1 inactivation and JAK3/STAT3 pathway activation could be independent events in the process of EN-NK/T-NT pathogenesis and progression, despite their possible influence on each other at the regulation level.

Stattic (38), a STAT3 inhibitor, inhibited cell viability and induced apoptosis in STAT3-mutant YT and NKL cells. However, Stattic had a low toxicity in NK92 cells with 

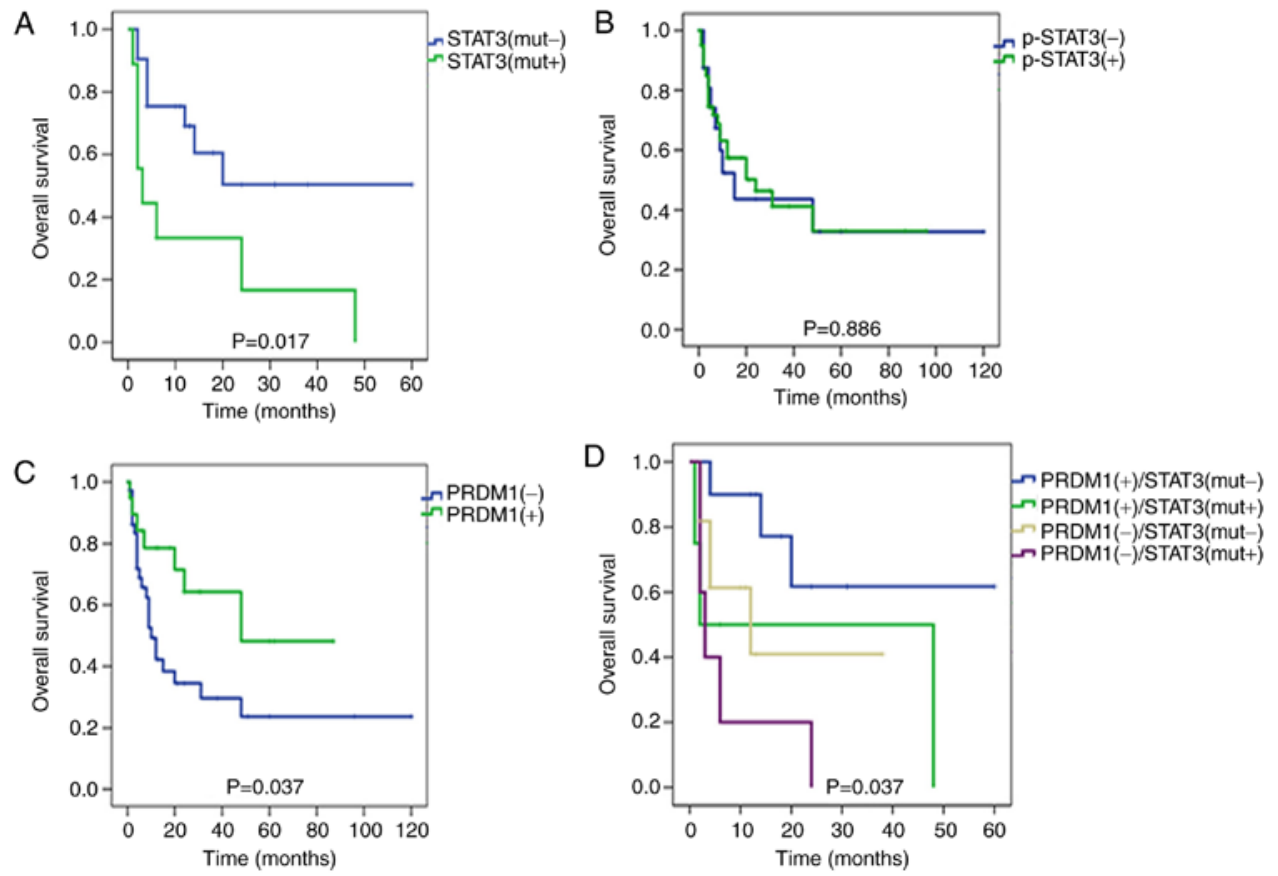

Figure 5. Stratified clinicopathological significance of STAT3 activation and PRDM1 expression in extranodal NK/T-cell lymphoma, nasal type. (A) Kaplan-Meier analysis demonstrated the correlation between STAT3 mutation and an inferior OS in patients ( $\mathrm{P}=0.017)$. (B) Kaplan-Meier analysis revealed that the p-STAT3 expression did not significantly affect OS $(\mathrm{P}=0.886)$. (C) Kaplan-Meier survival analysis revealed that PRDM1 expression in EN-NK/T-NT had a positive effect on OS ( $\mathrm{P}=0.037)$. (D) Kaplan-Meier analysis revealed the effect of PRDM1 expression and STAT3 mutation on OS. The group with STAT3(mut+)/PRDM1(-) staining had a considerably worse prognosis, as compared with that in other groups ( $\mathrm{P}=0.037)$. STAT3, signal transducer and activator of transcription 3; PRDM1, positive regulatory domain containing I; OS, overall survival; EN-NK/T-NT, extranodal NK/T-cell lymphoma, nasal type.
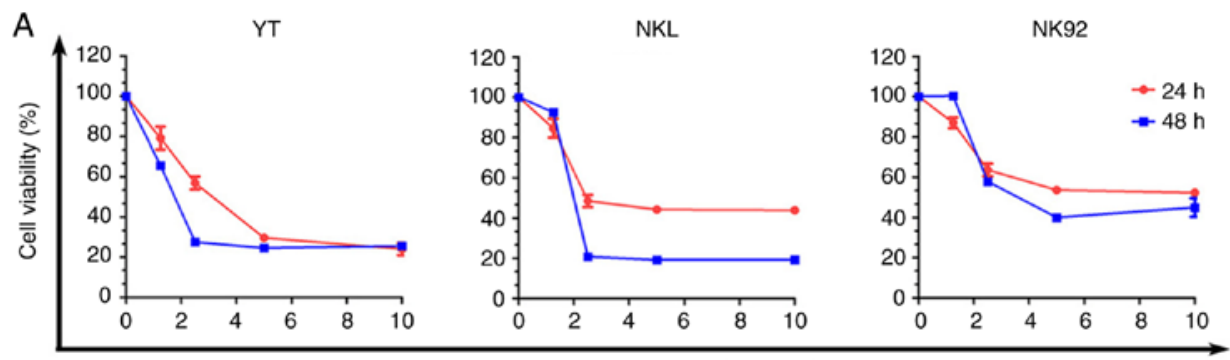

Concentration of stattic $(\mu \mathrm{mol} / \mathrm{l})$

B

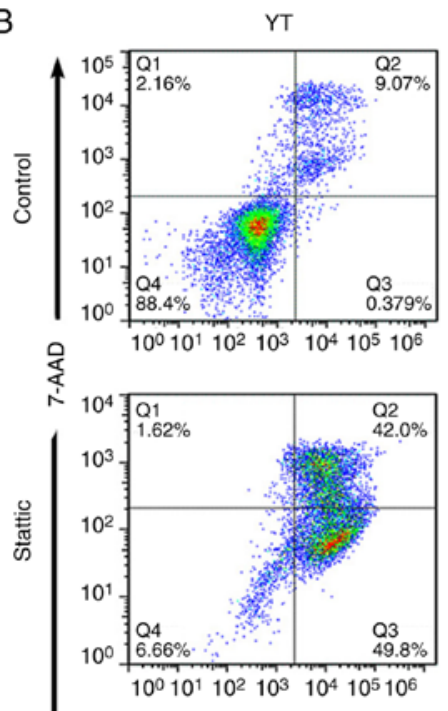

NKL
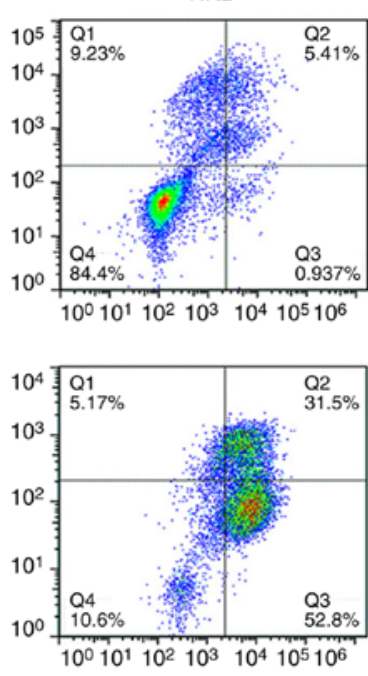

NK92
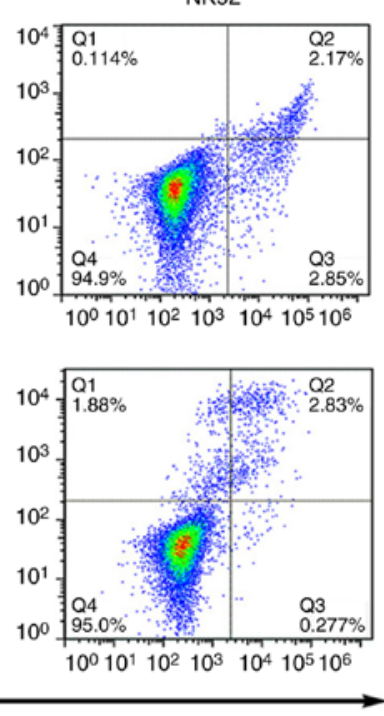

Figure 6. Stattic, a STAT3 inhibitor, affects STAT3-mutant cell growth and apoptosis. (A) NKL, NK92 and YT cells were treated with Stattic for the indicated concentrations and days, respectively. The proliferation of YT and NKL, but not those of NK92, was sensitive to $2 \mu$ M Stattic, as determined by MTS assay after 24 and $48 \mathrm{~h}$ of treatment. (B) Cells were treated with Stattic $(2 \mu \mathrm{M})$ for $48 \mathrm{~h}$ and the apoptosis of Stattic-treated cells was assessed by Annexin V/7ADD and tested with FACS. STAT3, signal transducer and activator of transcription 3. 
Table III. Correlation of p-STAT3 expression and STAT3 mutation with clinical factors and prognostic value.

\begin{tabular}{|c|c|c|c|c|c|c|c|c|c|c|}
\hline & \multicolumn{5}{|c|}{ p-STAT3 expression } & \multicolumn{5}{|c|}{ STAT3 mutation } \\
\hline & $\mathrm{n}$ & $\%$ & Low & High & P-value & $\mathrm{n}$ & $\%$ & No & Yes & P-value \\
\hline STAT3 mutation & 37 & & & & & & & & & \\
\hline Yes & 7 & 18.9 & 0 & 7 & 0.31 & & & & & \\
\hline No & 30 & 81.1 & 8 & 22 & & & & & & \\
\hline PRDM1 & 58 & & & & & 37 & & & & \\
\hline PRDM1(+) & 19 & 32.8 & 2 & 17 & NA & 15 & 40.5 & 13 & 2 & 0.39 \\
\hline PRDM1(-) & 39 & 67.2 & 14 & 25 & & 22 & 59.5 & 17 & 5 & \\
\hline Sex & 58 & & & & & 37 & & & & \\
\hline Male & 35 & 60.3 & 7 & 28 & 0.11 & 24 & 64.9 & 19 & 5 & 1.00 \\
\hline Female & 23 & 39.7 & 9 & 14 & & 13 & 35.1 & 11 & 2 & \\
\hline Age (years) & 58 & & & & & 37 & & & & \\
\hline$\leq 60$ & 44 & 75.9 & 15 & 29 & 0.11 & 26 & 70.3 & 19 & 7 & 0.08 \\
\hline$>60$ & 14 & 24.1 & 1 & 13 & & 11 & 29.7 & 11 & 0 & \\
\hline Site & 58 & & & & & 37 & & & & \\
\hline Nasal & 44 & 75.9 & 4 & 10 & 1.00 & 27 & 73 & 24 & 3 & 0.06 \\
\hline Extranasal & 14 & 24.1 & 12 & 32 & & 10 & 27 & 6 & 4 & \\
\hline Ann Arbor Stage & 36 & & & & & 17 & & & & \\
\hline $\mathrm{I} / \mathrm{II}$ & 10 & 27 & 4 & 6 & 0.69 & 5 & 29.4 & 5 & 0 & 0.26 \\
\hline III/IV & 27 & 73 & 8 & 19 & & 12 & 70.6 & 8 & 4 & \\
\hline Outcome & 50 & & & & & 35 & & & & \\
\hline Alive & 22 & 39.3 & 7 & 15 & 0.49 & 15 & 42.9 & 13 & 2 & 0.67 \\
\hline Dead & 34 & 60.7 & 8 & 26 & & 20 & 57.1 & 15 & 5 & \\
\hline Angiocentric infiltration & 58 & & & & & 37 & & & & \\
\hline No & 34 & 58.6 & 13 & 21 & 0.04 & 20 & 51.4 & 18 & 1 & 0.04 \\
\hline Yes & 24 & 41.4 & 3 & 21 & & 17 & 48.6 & 12 & 6 & \\
\hline Necrosis & 58 & & & & & 37 & & & & \\
\hline No & 20 & 34.5 & 7 & 13 & 0.36 & 16 & 43.2 & 14 & 2 & 0.67 \\
\hline Yes & 38 & 65.5 & 9 & 29 & & 21 & 56.8 & 16 & 5 & \\
\hline \multicolumn{11}{|l|}{ OS } \\
\hline Mean \pm SD & & & $23.56 \pm 31.9$ & $20.05 \pm 22.7$ & 0.69 & & & $16.41 \pm 15.02$ & $7.71 \pm 8.05$ & 0.05 \\
\hline
\end{tabular}

p-STAT3, phospho-STAT3 (Tyr705); STAT3, signal transducer and activator of transcription 3; PRDM1, positive regulatory domain containing I; OS, overall survival; NA, not analyzed.

wild-type STAT3 and did not affect apoptosis. Similarly, Stattic was effective against STAT3-mutant NTCL cells but less effective in STAT3 wild-type NTCL with a high p-STAT3 expression (30). At present, JAK inhibitors are expected to be effective in interrupting this signaling pathway in cells with a STAT3 expression (39). However, it is unclear whether the inhibitor may effectively inhibit this pathway in STAT3-mutant cells. Therefore, STAT3 mutant YT, NKL cells and WT NK92 cells were treated with tofacitinib, a pan-JAK inhibitor that has been revealed to have a functional specificity for JAK1/3 over JAK2 in cell assays (40). In consistency with the results of a previous study by Ando et al (41), tofacitinib was found to induce G1 CC arrest and inhibit cell growth in NK92 and STAT3-mutant cells. These data indicated that JAK1/3 inhibitors may have a therapeutic effect on EN-NK/T-NT patients with STAT3 mutations. Furthermore, tofacitinib has been approved by the US Food and Drug Administration for myeloproliferative disorders, and is therefore available for trials on patients with EN-NK/T-NT, while Stattic has still not been made clinically available (42). However, to facitinib blocks JAK3 activity in EN-NK/T-NT, both in vitro and in vivo, and its clinical usage in cancer therapy has been limited to pan-JAK inhibition activity (29). Further development of small-molecule inhibitors targeting STAT3 may synergize with highly selective JAK3 inhibitors to improve the outcome of these malignant diseases.

In conclusion, the activation of the JAK3/STAT3 pathway and inactivation of PRDM1 were two common events in EN-NK/T-NT observed in the samples of the present study. Notably, these two factors could stratify the clinicopathologic features of EN-NK/T-NT. In practice, PRDM1 immunostaining and STAT3 gene mutation could 
A

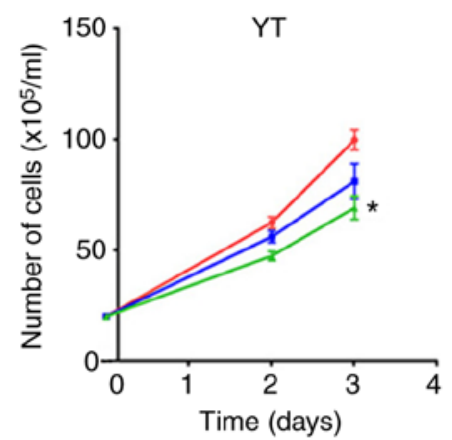

B

B
YT
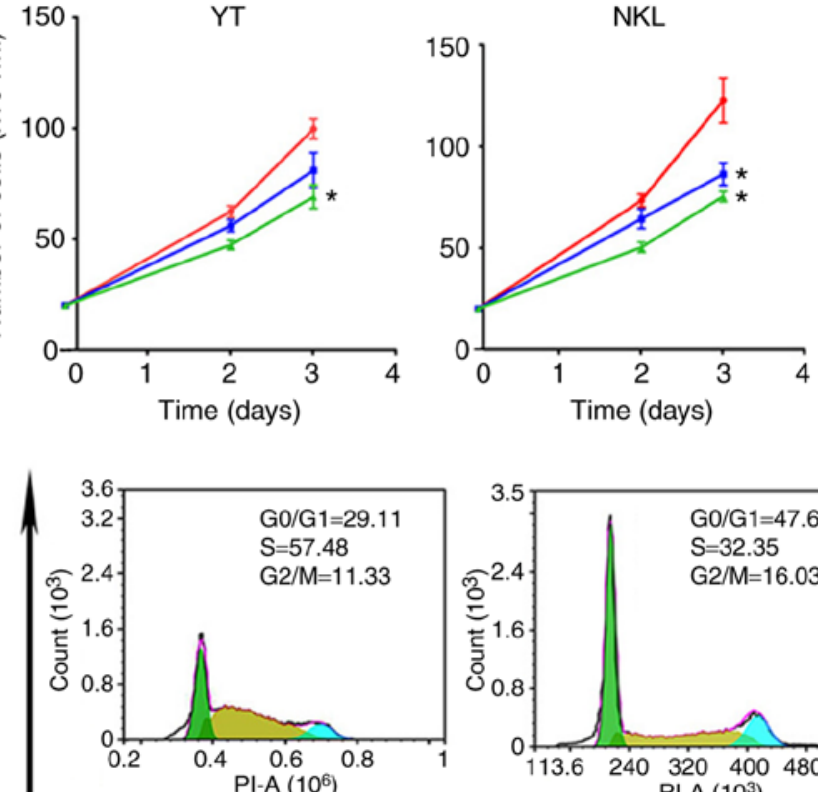

NK92

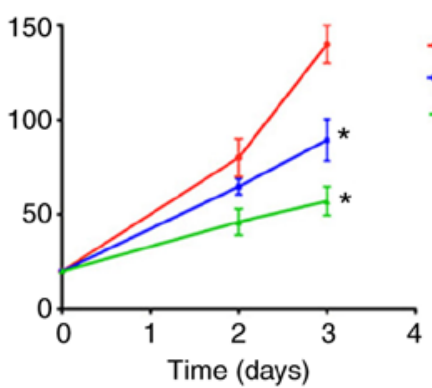

- DMSO

- Tofacitinb-50 nM

- Tofacitinb-100 nM
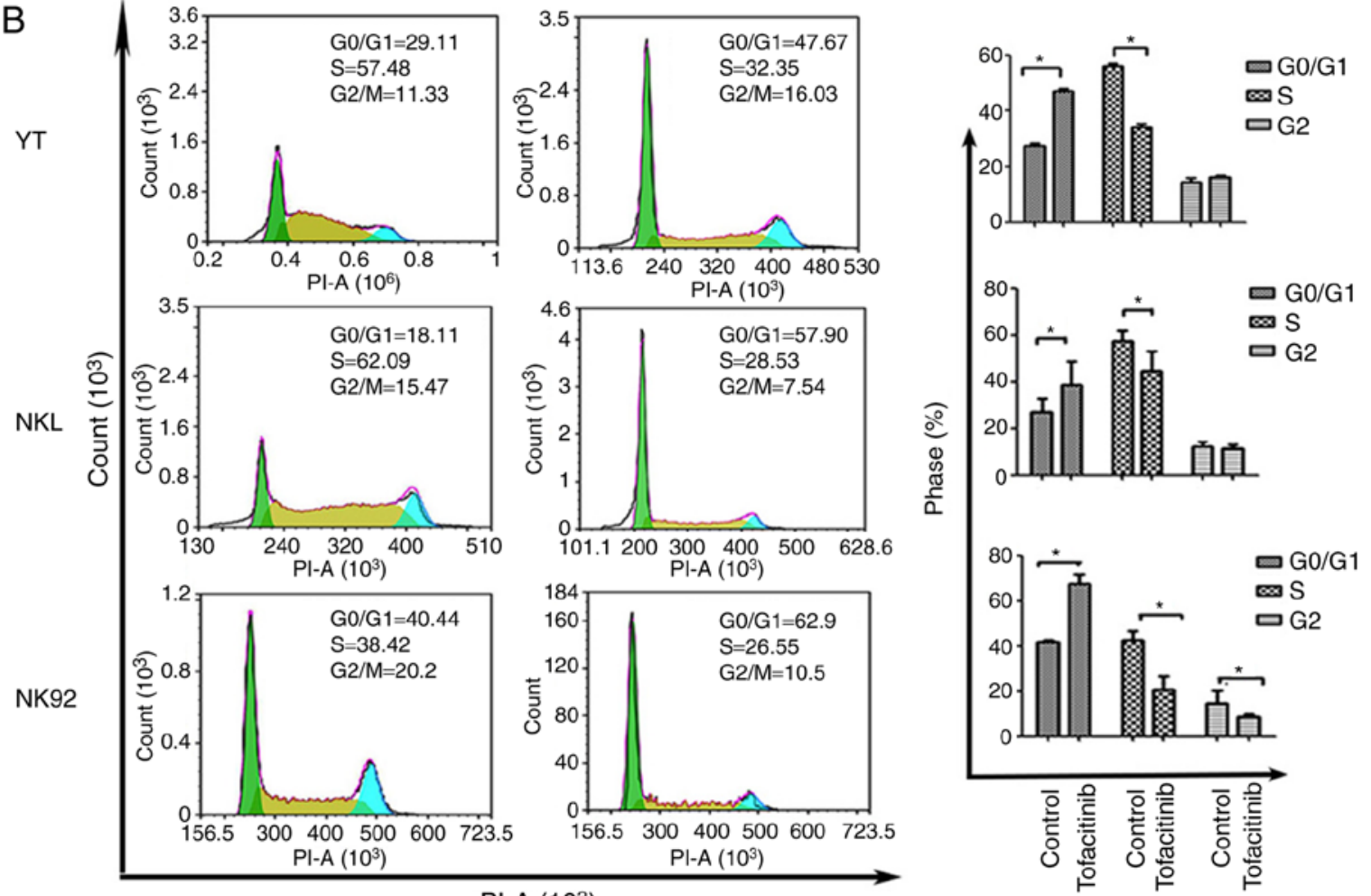

Control

$\mathrm{PI}-\mathrm{A}\left(10^{3}\right)$

Tofacitinib

Figure 7. Tofacitinib, a JAK3 inhibitor, affects EN-NK/T-NT cell growth and CC. (A) YT, NKL and NK92 cells were treated with the indicated concentrations of tofacitinib, and viable cells were counted at the indicated time-points, using the trypan blue exclusion test. Growth of YT, NKL, and NK92 cells were significantly inhibited following treatment with tofacitinib at 50 and $100 \mathrm{nM}$. Values are expressed as the means \pm SE of the results from at least 3 independent experiments, each with triplicate measurements $(\mathrm{n} \geq 3) ;{ }^{*} \mathrm{P}<0.05$ as compared with the DMSO-treated cells. (B) The 3 cell lines were treated with DMSO or $100 \mathrm{nM}$ tofacitinib for $48 \mathrm{~h}$, in order to assess CC profiles using flow cytometry. Following treatment, a significant increase was observed in the percentage of cells at the G1 phase and a concomitant reduction in the percentage of cells at the $\mathrm{S}$ and $\mathrm{G} 2$ phases in the 3 cell types. Values are presented as the mean $\pm \mathrm{SE}$ from triplicate experiments ( $\mathrm{P}<0.05$ as compared with DMSO-treated cells). EN-NK/T-NT, extranodal NK/T-cell lymphoma, nasal type; SE, standard error; DMSO, dimethyl sulfoxide; $\mathrm{CC}$, cell cycle.

serve as potential biomarkers for prognosis in patients with EN-NK/T-NT. In addition, the JAK3/STAT3 pathway inhibitor could be a new measure to deal with this highly aggressive malignancy.

\section{Acknowledgements}

Not applicable.

\section{Funding}

The present study was supported by a research grant from the National Nature Sciences Foundation of China (grant no. 81470359; Beijing, China).

\section{Availability of data and materials}

The datasets used during the present study are available from the corresponding author upon reasonable request.

\section{Authors' contributions}

TL and BZ conceived and designed the experiments. JL, LL and DL performed the experiments. LL and JL performed the data acquisition. LN, YZ and SH analyzed and interpreted the data. TL and JL wrote the paper. LN and LL were responsible for manuscript revision/review. All authors read and approved the manuscript and agree to be accountable for all aspects of the research in ensuring that the accuracy or 
integrity of any part of the work are appropriately investigated and resolved.

\section{Ethics approval and consent to participate}

This study was approved by the Institute Research Medical Ethics Committee of the ethical standards of the Medical Ethics Committee of Peking University First Hospital (approval no. 2013[571]). A written informed consent was obtained from the patients at the time of admission, with which the tissue, blood and other samples might be used for scientific research but did not relate to patient's privacy.

\section{Patient consent for publication}

Not applicable.

\section{Competing interests}

The authors declare that they have no competing interests.

\section{References}

1. Lee J, Kim WS, Park YH, Park SH, Park KW, Kang JH, Lee SS, Lee SI, Lee SH, Kim K, et al: Nasal-type NK/T cell lymphoma: Clinical features and treatment outcome. Br J Cancer 92: 1226-1230, 2005.

2. Tse $E$ and Kwong YL: The diagnosis and management of NK/T-cell lymphomas. J Hematol Oncol 10: 85, 2017.

3. Tse E and Kwong YL: How I treat NK/T-cell lymphomas. Blood 121: 4997-5005, 2013.

4. Makita S and Tobinai K: Clinical features and current optimal management of natural killer/T-cell lymphoma. Hematol Oncol Clin North Am 31: 239-253, 2017.

5. Iqbal J, Kucuk C, Deleeuw RJ, Srivastava G, Tam W, Geng H, Klinkebiel D, Christman JK, Patel K, Cao K, et al: Genomic analyses reveal global functional alterations that promote tumor growth and novel tumor suppressor genes in natural killer-cell malignancies. Leukemia 23: 1139-1151, 2009.

6. Karube K, Nakagawa M, Tsuzuki S, Takeuchi I, Honma K, Nakashima Y, Shimizu N, Ko YH, Morishima Y, Ohshima K, et al: Identification of FOXO3 and PRDM1 as tumor-suppressor gene candidates in NK-cell neoplasms by genomic and functional analyses. Blood 118: 3195-3204, 2011.

7. Küçük C, Iqbal J, Hu X, Gaulard P, De Leval L, Srivastava G, $\mathrm{Au}$ WY, McKeithan TW and Chan WC: PRDM1 is a tumor suppressor gene in natural killer cell malignancies. Proc Natl Acad Sci USA 108: 20119-20124, 2011.

8. Huang Y, de Leval L and Gaulard P: Molecular underpinning of extranodal NK/T-cell lymphoma. Best Pract Res Clin Haematol 26: 57-74, 2013.

9. Liang L, Nong L, Zhang S, Zhao J, Ti H, Dong Y, Zhang B and Li T: The downregulation of PRDM1/Blimp-1 is associated with aberrant expression of miR-223 in extranodal NK/T-cell lymphoma, nasal type. J Exp Clin Cancer Res 33: 7, 2014.

10. Liang L, Zhang Z, Wang Y, Nong L, Zheng Y, Qu L, Zhang B and $\mathrm{Li}$ T: The genetic deletion of $6 \mathrm{q} 21$ and PRDM1 and clinical implications in extranodal NK/T cell lymphoma, nasal type. Biomed Res Int 2015: 435423, 2015.

11. Zhang Z, Liang L, Li D, Nong L, Liu J, Qu L, Zheng Y, Zhang B and Li T: Hypermethylation of PRDM1/Blimp-1 promoter in extranodal NK/T-cell lymphoma, nasal type: An evidence of predominant role in its downregulation. Hematol Oncol 35: 645-654, 2017.

12. Lee S, Park HY, Kang SY, Kim SJ, Hwang J, Lee S, Kwak SH, Park KS, Yoo HY, Kim WS, et al: Genetic alterations of JAK/STAT cascade and histone modification in extranodal NK/T-cell lymphoma nasal type. Oncotarget 6: 17764-17776, 2015.

13. Ng SB, Selvarajan V, Huang G, Zhou J, Feldman AL, Law M, Kwong YL, Shimizu N, Kagami Y, Aozasa K, et al: Activated oncogenic pathways and therapeutic targets in extranodal nasal-type NK/T cell lymphoma revealed by gene expression profiling. J Pathol 223: 496-510, 2011.
14. Wang Y, Shen Y, Wang S, Shen Q and Zhou X: The role of STAT3 in leading the crosstalk between human cancers and the immune system. Cancer Lett 415: 117-128, 2018.

15. Chen YW, Guo T, Shen L, Wong KY, Tao Q, Choi WW, Au-Yeung RK, Chan YP, Wong ML, Tang JC, et al: Receptor-type tyrosine-protein phosphatase $\kappa$ directly targets STAT3 activation for tumor suppression in nasal NK/T-cell lymphoma. Blood 125: $1589-1600,2015$

16. Coppo P, Gouilleux-Gruart V, Huang Y, Bouhlal H, Bouamar H, Bouchet S, Perrot C, Vieillard V, Dartigues P, Gaulard P, et al: STAT3 transcription factor is constitutively activated and is oncogenic in nasal-type NK/T-cell lymphoma. Leukemia 23: 1667-1678, 2009.

17. Küçük C, Jiang B, Hu X, Zhang W, Chan JK, Xiao W, Lack N, Alkan C, Williams JC, Avery KN, et al: Activating mutations of STAT5B and STAT3 in lymphomas derived from $\gamma \delta-T$ or NK cells. Nat Commun 6: 6025, 2015.

18. Cazzola M: Introduction to a review series: The 2016 revision of the WHO classification of tumors of hematopoietic and lymphoid tissues. Blood 127: 2361-2364, 2016.

19. Robertson MJ, Cochran KJ, Cameron C, Le JM, Tantravahi R and Ritz J: Characterization of a cell line, NKL, derived from an aggressive human natural killer cell leukemia. Exp Hematol 24: 406-415, 1996.

20. Gong JH, Maki G and Klingemann HG: Characterization of a human cell line (NK-92) with phenotypical and functional characteristics of activated natural killer cells. Leukemia 8: 652-658, 1994.

21. Yodoi J, Teshigawara K, Nikaido T, Fukui K, Noma T, Honjo T, Takigawa M, Sasaki M, Minato N, Tsudo M, et al: TCGF (IL-2)-receptor inducing factor(s). I. Regulation of IL 2 receptor on a natural killer-like cell line (YT cells). J Immunol 134: 1623-1630, 1985.

22. Garcia JF, Roncador G, Garcia JF, Sánz AI, Maestre L, Lucas E, Montes-Moreno S, Fernandez Victoria R, MartinezTorrecuadrara JL, Marafioti T, et al: PRDM1/BLIMP-1 expression in multiple B and T-cell lymphoma. Haematologica 91: 467-474, 2006.

23. Nie K, GomezM,LandgrafP,GarciaJF,Liu Y,TanLH,Chadburn A, Tuschl T, Knowles DM and Tam W: MicroRNA-mediated down-regulation of PRDM1/Blimp-1 in Hodgkin/Reed-Sternberg cells: A potential pathogenetic lesion in Hodgkin lymphomas. Am J Pathol 173: 242-252, 2008.

24. Nie K, Zhang T, Allawi H, Gomez M, Liu Y, Chadburn A, Wang YL, Knowles DM and Tam W: Epigenetic down-regulation of the tumor suppressor gene PRDM1/Blimp-1 in diffuse large B cell lymphomas: A potential role of the microRNA let-7. Am J Pathol 177: 1470-1479, 2010.

25. Yuan J, Zhang F and Niu R: Multiple regulation pathways and pivotal biological functions of STAT3 in cancer. Sci Rep 5: $17663,2015$.

26. Wu ZL, Song YQ, Shi YF and Zhu J: High nuclear expression of STAT3 is associated with unfavorable prognosis in diffuse large B-cell lymphoma. J Hematol Oncol 4: 31, 2014.

27. Khanna P, Chua PJ, Bay BH and Baeg GH: The JAK/STAT signaling cascade in gastric carcinoma (Review). Int J Oncol 47: $1617-1626,2015$.

28. Bouchekioua A, Scourzic L, de Wever O, Zhang Y, Cervera P, Aline-Fardin A, Mercher T, Gaulard P, Nyga R, Jeziorowska $\mathrm{D}$, et al: JAK3 deregulation by activating mutations confers invasive growth advantage in extranodal nasal-type natural killer cell lymphoma. Leukemia 28: 338-348, 2014.

29. Nairismägi M, Gerritsen ME, Li ZM, Wijaya GC, Chia BKH, Laurensia Y, Lim JQ, Yeoh KW, Yao XS, Pang WL, et al: Oncogenic activation of JAK3-STAT signaling confers clinical sensitivity to PRN371, a novel selective and potent JAK3 inhibitor, in natural killer/T-cell lymphoma. Leukemia 32: 1147-1156, 2018.

30. Sim SH, Kim S, Kim TM, Jeon YK, Nam SJ, Ahn YO, Keam B, Park HH, Kim DW, Kim CW and Heo DS: Novel JAK3-activating mutations in extranodal NK/T-cell lymphoma, nasal type. Am J Pathol 187: 980-986, 2017.

31. Xu Y, Shi Y, Yuan Q, Liu X, Yan B, Chen L, Tao Y and Cao Y: Epstein-Barr virus encoded LMP1 regulates cyclin D1 promoter activity by nuclear EGFR and STAT3 in CNE1 cells. J Exp Clin Cancer Res 32: 90, 2013.

32. Dobashi A, Tsuyama N, Asaka R, Togashi Y, Ueda K, Sakata S, Baba S, Sakamoto K, Hatake K and Takeuchi K: Frequent BCOR aberrations in extranodal NK/T-Cell lymphoma, nasal type. Genes Chromosomes Cancer 55: 460-471, 2016. 
33. Jiang L, Gu ZH, Yan ZX, Zhao X, Xie YY, Zhang ZG, Pan CM, $\mathrm{Hu}$ Y, Cai CP, Dong Y, et al: Exome sequencing identifies somatic mutations of DDX3X in natural killer/T-cell lymphoma. Nat Genet 47: 1061-1066, 2015.

34. Koo GC, Tan SY, Tang T, Poon SL, Allen GE, Tan L, Chong SC, Ong WS, Tay K, Tao M, et al: Janus kinase 3-activating mutations identified in natural killer/T-cell lymphoma. Cancer Discov 2: 591-597, 2012

35. Kimura H, Karube K, Ito Y, Hirano K, Suzuki M, Iwata S and Seto M: Rare occurrence of JAK3 mutations in natural killer cell neoplasms in Japan. Leuk Lymphoma 55: 962-963, 2014.

36. Ryu JG, Lee J, Kim EK, Seo HB, Park JS, Lee SY, Moon YM, Yoo SH, Park YW, Park SH, et al: Treatment of IL-21R-Fc control autoimmune arthritis via suppression of STAT3 signal pathway mediated regulation of the Th17/Treg balance and plasma B cells. Immunol Lett 163: 143-150, 2015.

37. Barnes NA, Stephenson S, Cocco M, Tooze RM and Doody GM: BLIMP-1 and STAT3 counterregulate microRNA-21 during plasma cell differentiation. J Immunol 189: 253-260, 2012.

38. Heidelberger S, Zinzalla G, Antonow D, Essex S, Basu BP Palmer J, Husby J, Jackson PJ, Rahman KM, Wilderspin AF, et al: Investigation of the protein alkylation sites of the STAT3:STAT3 inhibitor Stattic by mass spectrometry. Bioorg Med Chem Lett 23: 4719-4722, 2013
39. Quintás-Cardama A and Verstovsek S: Molecular pathways: Jak/STAT pathway: Mutations, inhibitors, and resistance. Clin Cancer Res 19: 1933-1940, 2013.

40. Banerjee S, Biehl A, Gadina M, Hasni S and Schwartz DM: JAK-STAT signaling as a target for inflammatory and autoimmune diseases: Current and future prospects. Drugs 77: 521-546, 2017.

41. Ando S, Kawada JI, Watanabe T, Suzuki M, Sato Y, Torii Y, Asai M, Goshima F, Murata T, Shimizu N, et al: Tofacitinib induces G1 cell-cycle arrest and inhibits tumor growth in Epstein-Barr virus-associated T and natural killer cell lymphoma cells. Oncotarget 7: 76793-76805, 2016.

42. Vainchenker W, Leroy E, Gilles L, Marty C, Plo I and Constantinescu SN: JAK inhibitors for the treatment of myeloproliferative neoplasms and other disorders. F1000Res 7: 82, 2018.

This work is licensed under a Creative Commons Attribution-NonCommercial-NoDerivatives 4.0 International (CC BY-NC-ND 4.0) License. 